\title{
GREEN ECONOMY IN SUSTAINABLE DEVELOPMENT AND IMPROVEMENT OF RESOURCE EFFICIENCY
}

\author{
Mikhno, I., Koval, V., Shvets, G., Garmatiuk, O., Tamošiūnienė, R.
}

Inesa Mikhno / Private Higher Educational Institution "European University", 42B Glushkova str., 02000 Kyiv, Ukraine.Email: inessa.mihno@gmail.com

Viktor Koval / Odessa Institute of Trade and Economics of Kyiv National University of Trade and Economics, 6, Inglezi str., 65070 Odessa, Ukraine.Email: victor-koval@ukr.net

Galyna Shvets / State Higher Educational Establishment "Pryazovskyi State Technical University", 87500 Mariupol, Donetsk region, Ukraine.Email: shvetsg@gmail.com

Oksana Garmatiuk / Ternopil Ivan Puluj National Technical University, 56 Ruska St., 46001 Ternopil, Ukraine.Email:kafec@ukr.net

Rima Tamošiūnienè / Vilnius Gediminas Technical University, Sauletekio ave. 11, LT-01225 Vilnius, Lithuania. Email: rima.tamosiuniene@vgtu.It

\begin{abstract}
In the expansion of volumes of industrial production, there is an increase of anthropogenic influence and deterioration of the external environment that became the reason for the impossibility of a functioning market system without taking into account negative externalities. The article considers the directions and principles of a "green economy" functioning as the basis for further development of society. The current state and trends of the impact of environmental factors on other indicators of quality of life have been analysed and comparative analysis has been made on the example of developed and developing countries. Effective indices and instruments of influence on the level of ecological and economic development and main tendencies and problems arising at the introduction of "green economy", have been considered. The use of indicators that take into account negative externalities, such as the Pigouvian tax, has been demonstrated to be more visible than widely used indices. The losses from the negative impact on the resulting economic indicators have been analysed, and a significant decrease in the per capita GDP level has been proved with the extensive development of the economy.

Implications for Central European audience: This paper aims to contribute to the development of a green economy as part of a policy aimed at reducing environmental risks in the process of economic growth. The proposed indicators and tools for influencing the level of environmental and economic development arising from the implementation of the "green economy" as the main vector of sustainable development, which can be used further research and development and can be implemented by European companies.
\end{abstract}

Keywords: green economy; Pigouvian tax; negative externalities; resource efficiency JEL Classification: L26, Q56 


\section{Introduction}

The development of technologies and the increase in anthropogenic impact on the environment contributes to the creation of new relationships between humans and the ecosystem and changes that are resulting indicators of their interaction. Increasingly, economically developed countries are characterised not by the availability of resource potential, but by a developed system of services, in particular in the financial sector, and a high level of well-being of the population, one of the evaluation criteria of which is the environmental component.

So the research aims to investigate effective indicators taking into account negative externalities and the impact of environmentally friendly technologies on the development of the "green economy".

The article uses methods of economic and mathematical modelling, comparison, induction and deduction, forecasting, etc.

In conditions of depletion of natural resources and depletion of natural capital, man-made deposits, production and consumption, waste can be considered as a resource basis for modernisation (Potravny et al., 2016).

Strengthening of the integration is due to increase support from the European Union for the introduction of renewable energy in Ukraine. This arose at the turn of the century after the signing of the Kyoto Protocol, which led to the creation of single world space and the introduction of a stronger and more coordinated train of measures as a result of the 1997 White Paper. In Japan, energy efficiency is the best strategy, the basis of which includes not only the demand and supply policy but also both activities aimed at technology, provide direct incentives to invest in innovative activities (Mancusi et al., 2018).

"Green" technologies are becoming the subject of growing discussion; the "green dimension" is becoming a clear institutional logic that can be used by sharing platforms to attract environmentally conscious users and achieve legitimacy in the eyes of sustainable development, oriented local authorities and investors (Kostetska Khumarova et al., 2020; Sikdar, 2003). The dominance of "green" logic over any other logic can be viable at an early stage of the startup process; when re-balancing and integrating other logics, special expenses are required for longer-term growth (Grinevich et al., 2019).

Neural networks can be used to fully approximate any complex non-linear functions. As parallel distributed processing algorithms, they can be used for fast and real-time calculation of the neural network identification model in real-time (He, 2018; Yankovyi et al., 2019).

As entrepreneurs require various forms of financing as their business grows and moves up, the role of supporting the public sector in obtaining grants, equity and new forms of financing in high and low-income countries is important. These funds can provide sustainability-oriented businesses with access to finance and encourage financing in new areas through a demonstration effect. An approach to the financing ecosystem that provides complementary forms of financing for low-carbon investments at the local, national 


\section{DISCUSSION}

and international levels is necessary, along with support for the development of entrepreneurial skills and investment preparedness (Owen et al., 2018).

As the process of introducing "green technologies" continues slowly, and this is especially noticeable in developing countries, the question of the existence of the "green economy" remains open, and its implementation has several problems that do not guarantee a complete transition to its implementation.

\section{Theoretical aspects of the development of the green economy}

In the world, the "green economy" is understood as a dynamic process of economic transformation in the direction of low-carbon development, increasing resource efficiency and well-being of the population by the usage of technologies and innovations that create new jobs while reducing environmental risks in the long term (Frone \& Frone, 2015).

Consider the guidelines for the development of the "green economy" in Figure 1.

Figure 1 | Directions of the green economy

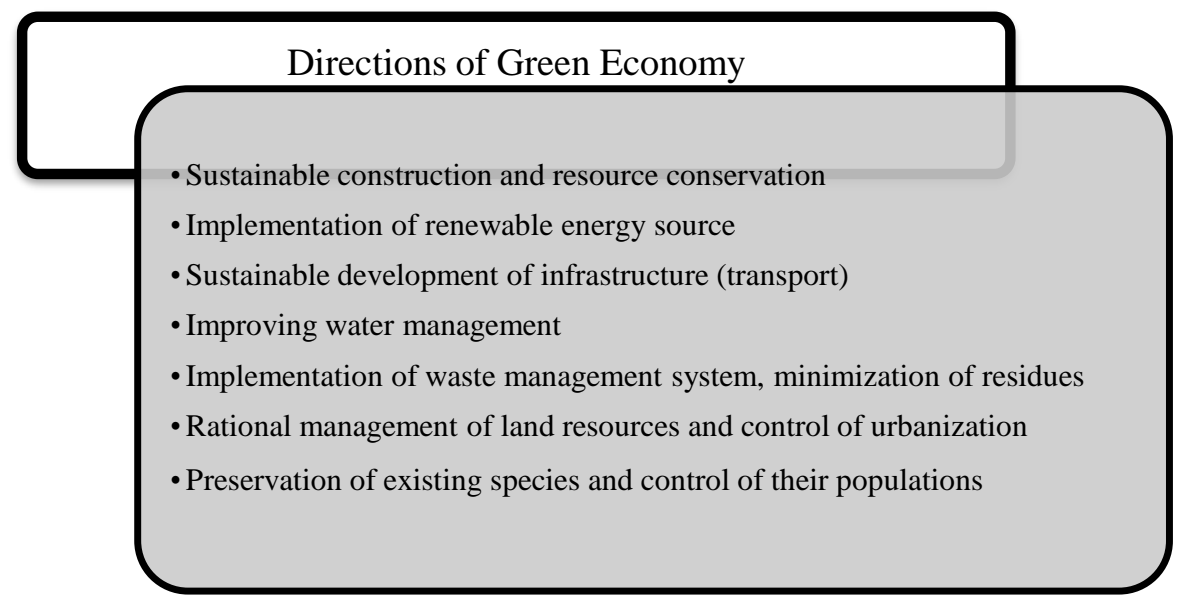

Source: prepared by the authors based on Saeed (2018)

Opportunities for introducing the latest technologies and developing the "green economy" in the world are becoming available every year. However, economic development mainly affects their availability. Developed countries with high GDP per capita are more often implementing environmental conservation programs while developing countries and countries with low living standards are outsiders in introducing new technologies. One of the problems in developing countries is the unwillingness of the state and enterprises to change technologies and invest in environmental conservation, while development takes place by using the ecosystem (extensive methods), which are designed for environmental degradation and the absence of strategic planning, does not take into account the negative 
impact and cumulative effect, thereby reducing the welfare of the population and the country's potential.

No country has yet been able to transform the economy into "green". However, developed countries have a significantly higher level of introduction of environmentally friendly technologies and constant monitoring of compliance with already established standards. There are a fairly large number of public policy instruments to increase the rate of implementation of the green economy, some of which are not purely economic. In a market economy, where revenues are the main indicator of profitability, it is the state that should regulate key sectors for introducing sustainable development (Yeshchenko et al., 2019). The main tools to stimulate the "green economy" and equalise the competitive environment include (Dabyltayeva \& Rakhymzhan, 2019; Saeed, 2018):

- The introduction of subsidies and donations to enterprises with minimal negative impact on the environment, and vice versa, an increase in taxes and penalties for non-compliance with established standards.

- Increasing control over the activities of enterprises with environmental impact and constant diagnostics of the ecosystem.

- Improving the management and communication system between all business entities (segments of the population), creating interactive maps in all areas of the development of the "green economy", and creating a quick response group to complaints sent.

- Any encouragement from the state and the population in order to focus on the ecosystem and increase the demand for goods in the production of which environmentally friendly technologies were used.

- Transparency of data on production technologies and the impact of economic entities on the ecosystem, the fight against the monopolisation of the market and the creation of free competition, where the priority is to maintain the ecological state, adjust information policy.

- The creation of open competitions and the usage of grant programs aimed at developing a green economy and circular economy (D'Amato et al., 2019; Rodriguez-Anton et al., 2019; Schroeder et al., 2019).

In Ukraine and developing countries, there is the problem of lobbying for laws, distortion of information and illegal business aimed to maximise profits. All this complicates the process of analysing markets and forecasting the situation for the future.

In world practice, the term social investment is gaining popularity. The process of introducing social investment forms a priority for the development of a person and the conditions of his life, putting the ecosystem in priority; however, in Ukraine, it is still at a low level, while the usage of grant funds to preserve the environment is growing, this indicates a low public responsibility and disinterest in preserving the environment.

Recently, the Pigouvian tax began to be used. This is a tax on any assets in the market that generates negative external effects (expenses are not included in the market price). The tax is intended to correct an undesirable or ineffective market result (market failure) and does this by setting the social value of negative external factors equal. In the presence of negative external factors, the social costs of market activity are not covered by the private 
costs of this activity. In this case, the market result is inefficient and may lead to excessive consumption of the product (Sandmo, 2008). According to the Environmentally Adjusted Multifactor Productivity coefficient, which takes into account the contribution to the development of natural investment and the reduction of excess production (environmentally adjusted production), many countries have a negative value, that is, development comes from the usage of natural resources and is not used for its intended purpose, but becomes waste. According to estimates, before 2013, Ukraine had an average of this indicator at the level of -2 , which means that he ecosystem was deteriorating and its potential was used without restoration, but there was no overproduction, which increases waste, while according to other indicators that take into account negative externalities, economic development was also negative, that is, occurred by extensive methods (Koval et al., 2019).

\section{Approaches to assessing the development of the green economy and the direction of its stimulation}

According to Environmentally Adjusted Multifactor Productivity data, we can monitor global trends in the countries of the world (2001 - increase in overproduction, 2009 - decrease), caused by the transfer of resources to reduce pollution, or the introduction of "excess" growth, which is created due to the quality of the environment to other sources of financing (OECD, 2019).

The article considers countries that are similar in terms of living standards and emerging problems in society (Russia, Ukraine), neighbouring countries, close in geographical location (Russia, Ukraine, Poland), developed European countries that allocate funds for resource conservation and quality preservation environment, have ecologically oriented legislation (Germany, France), innovatively advanced countries of the world (Japan, USA), ecologically dangerous countries, where the creation of goods is due to the deterioration of the ecological environment (China). Of course, the deterioration of the environment is not the main cause of mortality. However, it can affect the quality of life by increasing morbidity, reducing immunity. Unsatisfactory ecological status affects flora and fauna of regions, changing ecosystems. In recent years, due to excessive use of fertilisers on agricultural land, there has been an accumulation of harmful chemical compounds in the soil, their entry into groundwater and the emergence of soil erosion, which is the cause of increasing deserts in the world. The use of outdated technologies is not only less environmentally friendly but also higher in cost. As the cost of goods increases, so does the selling price of goods, so it becomes less competitive and accessible to the general population. A decrease in the selling price of goods increases the risk of the company becoming unprofitable and reduces the likelihood of introducing new technologies. With the deterioration of product quality due to cheaper resource component, it also becomes less competitive in the market. Developed countries allocate more funds for environmental projects, support for "green" enterprises and improve working conditions, which has a positive effect on the country's overall trend in macroeconomic indicators and increases social welfare, thereby reducing morbidity caused by environmental factors and injuries in enterprises. Deterioration of the ecosystem is one of the causes of premature mortality (Newton \& Cantarello, 2014). 
The deterioration of the ecosystem leads to an increase in morbidity and mortality, thereby reducing the country's labour potential and increase spending on social programs (in case of incapacity for work, disability, etc.). These countries have been selected since Russia and Poland borders Ukraine and has many similar resources and histories. France is similar in the territory and located in Europe and is geographically similar, but different in living standards. China is one of the fastest economies, but it is very polluting. This is a negative example since the level of waste is higher than the increase in income. Germany is an example of Europe and is very accurate in enforcing legislation where Ukraine needs to strive. Consider the increase in the rate of premature mortality due to environmental degradation in different countries (Figure 2). Most often, this is due to the incidence of malignant tumours and cardiovascular diseases.

Figure 2 | Welfare cost of premature deaths, \% GDP equivalent in the country

\section{WELFARE COST OF PREMATURE DEATHS, \% GDP EQUIVALENT}

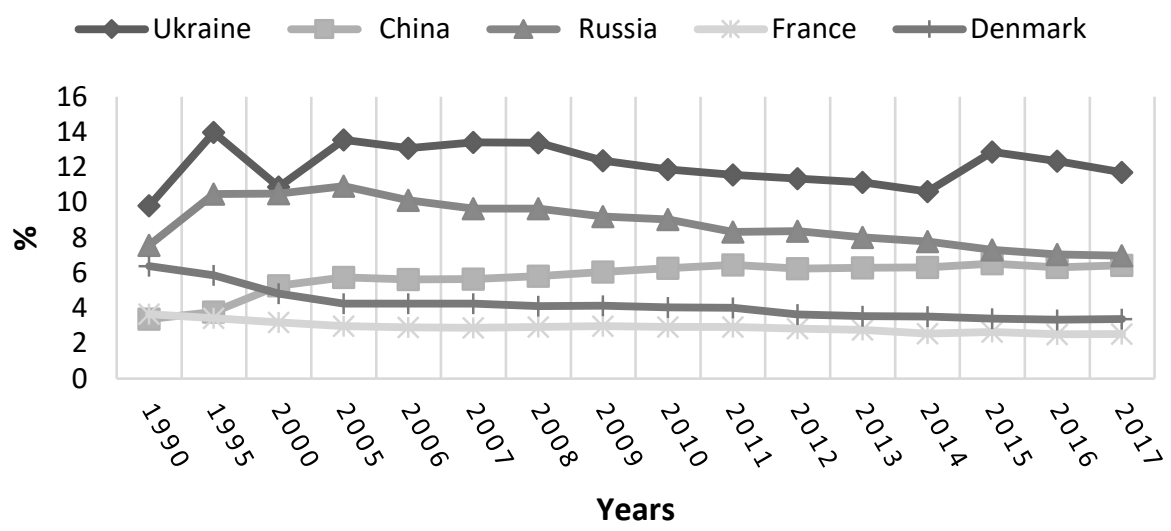

Source: Prepared by the authors based on OECD (2019)

From Figure 2, it is seen that Ukraine is a leader in premature mortality due to environmental degradation. This illustrates the situation when, even with the availability of funds and the availability of grant programs from world funds, the funds are not used for their intended purpose, or the actions are targeted and do not lead to significant shifts in the time interval. Such countries as Canada, France and Denmark have positive trends (we observe a decrease in premature mortality in the time interval) and significantly lower rates than in such countries as Russia, Ukraine, China, where the usage of natural potential is spontaneous, and development is due to deterioration ecosystems. This indicator correlates with the economic situation in the country and illustrates the quality of life of the population.

One of the indicators of air pollution is the number of solids in the air of about 2.5 microns, which are created mainly due to the operation of industrial enterprises, a large number of vehicles with a low degree of filtration and in the presence of soil erosion. According to the World Health Organization (WHO), the average annual level of PM2.5 should not exceed 


\section{DISCUSSION}

$10 \mu \mathrm{g} / \mathrm{m} 3$, and the average daily level should not exceed $25 \mu \mathrm{g} / \mathrm{m} 3$. Currently, there is an online platform for monitoring the state of the world's air - The World Air Quality Index —, which helps to assess the situation in a given region in a timely manner and to act in case of excessive concentrations of pollutants.

We will examine the number of solid particles pm 2.5 in the air (Fig. 3), which is an indicator of air pollution and is associated with a long-term mortality rate from diseases of the cardio and respiratory systems. The most sensitive to this factor of influence are children and the population over 60 years of age. Therefore, this indicator is one of the indicators of the quality of life of the population and an indicator of the introduction of "green" technologies in a particular country.

Figure 3 | Environmental dimension of quality of life - mean population exposure to PM 2.5

\section{MEAN POPULATION EXPOSURE TO PM2.5, MICROGRAMS PER CUBIC METRE}

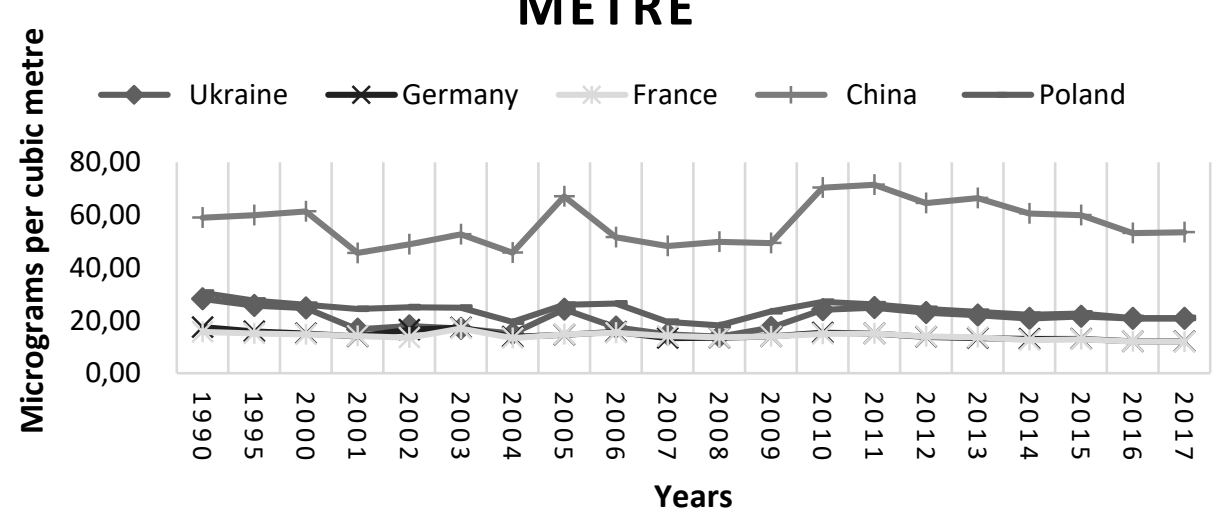

Source: Prepared by the authors based on OECD (2019)

From Figure 3, it is seen that the greatest pollution is observed in China, where about 50 micrograms of solid particles are found in 1 cubic meter. After an increase in production in 2011, a decrease in pollution is observed; however, its level remains high. The development of products based on the use of natural resources and the constant creation of new products to increase profits without taking into account the impact on the ecosystem is cumulative and can lead to increased morbidity and mortality. The best situation is in such countries as Sweden, the USA and Canada, where production proceeds only in accordance with sanitary and epidemiological standards and the level of pollution is constantly monitored. However, large countries such as the United States and Canada are uneven in terms of environmental impact, so in some states, there are problems of environmental protection and compliance with living standards, while Sweden - a country with a small area, focused on innovation - is a country of digital technologies and their implementation, has a high standard of living due to the favourable economic and 
investment climate and is aimed at the development of green economy and resourcesaving technologies. In such countries as Poland and Ukraine, which are nearby and affect each other, the pollution level is quite high and remains constant over the long term, which indicates the slow movement of the introduction of modern technologies with minimisation of environmental pollution.

The introduction of the "green economy" is impossible without improving technology and innovative development. Countries such as Ukraine have a slow pace of change due to lack of funds and the usage of outdated technologies, while they can be profitable. The presence of corruption also slows the introduction of positive change. An example is a situation with waste management, where the landfill prevails as a method of disposal. Entrepreneurs who generate income from landfill lobby for interests in government. They do not comply with sanitary and epidemiological standards (MSW-5, 6 (Kyiv)) and prevent foreign investors from investing in the construction of modern waste recycling plants. The legislation has not yet been agreed to provide for fractional processing and sorting of garbage. All this leads to a worsening of the problem, which gets worse every year. The decision and discussion as a whole are prescriptive and do not fundamentally change the situation that has developed.

Will examine the share of environmentally friendly technologies in various countries of the world that are being introduced in the overall structure of technological changes as an indicator of the "green economy" implementation (Figure 4).

Figure 4 | Development of environment-related technologies, \% all technologies (OECD, 2019)

\section{DEVELOPMENT OF ENVIRONMENT-RELATED TECHNOLOGIES, \% ALL TECHNOLOGIES}

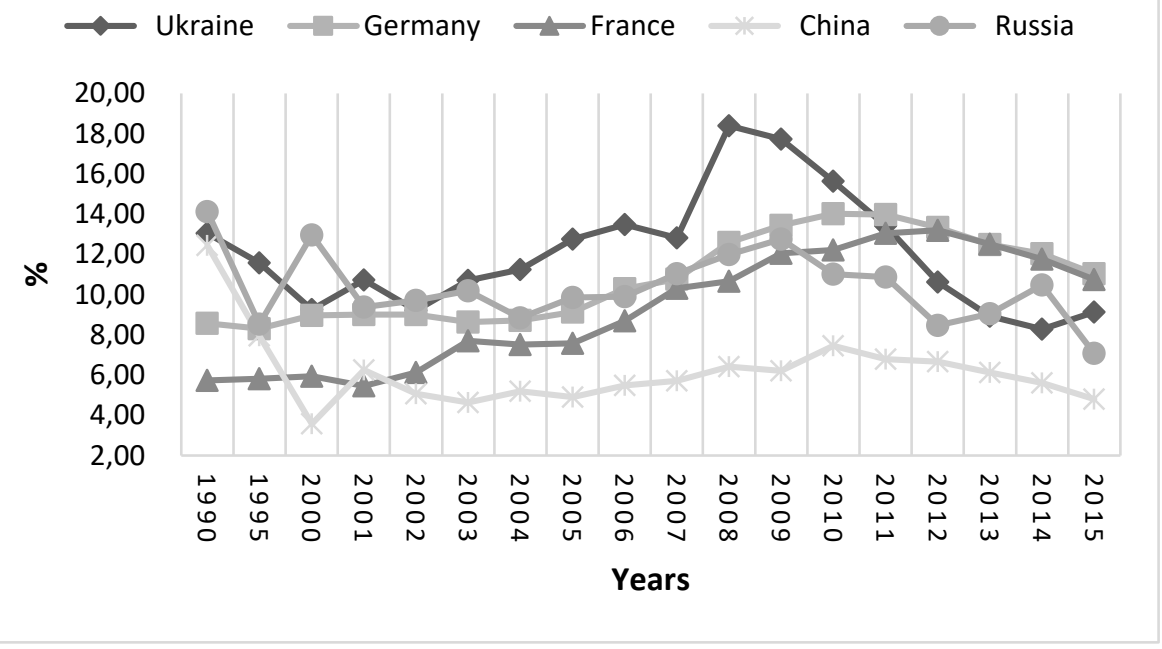

Source: Prepared by the authors based on OECD (2019)

Environmentally friendly technologies are a market segment of technologies, means of production and services that contribute to the efficient use of available resources, as well as the protection and conservation of natural resources and are in increasing demand in the 


\section{DISCUSSION}

world. However, real implementations reflect the picture only in the transparent usage of funds and the absence of corruption, which is not typical for nowadays Ukraine.

However, if you take into account all the costs associated with environmental losses, this figure will be much lower, and even real GDP is inflated, so it is advisable to use a new indicator that would calculate the growth rate for each company, taking into account the cost of environmental recovery. And although innovation in the life of the state is a growth factor reflected in the available indicators, many countries (including China) would have negative adjusted indicators of gross domestic product per capita, and harmful enterprises could be easily monitored and help entrepreneurs change technologies and develop in the direction of ecosystem conservation.

From Figure 4, it is seen that since 2002 in all the studied countries, there has been an increase in the percentage of "green technologies", however, since 2011, we see their reduction, which indicates an investment in more harmful production and a reduction in the cost of modernisation. The best situation is observed in France and Germany, that illustrates a constant increase in environmental technologies and even in 2015, a slight decline to $11 \%$, while the percentage of environmentally friendly technologies in China remains quite low with an overall increase in production and a constant expansion of spheres of activity. In Ukraine, a sufficiently large percentage of the introduction of clean technologies was observed till 2011 and 2008 was the extreme point. However, in recent years there has been a significant decline and a decrease in the pace of modernisation. A percentage of more than 10 indicates a change in technology and the usage of grant funds for environmental improvement, but large investments do not guarantee results in a country where information is not adequate but may change under the influence of political and economic factors. In general, the usage of clean technologies is observed in large enterprises owned by oligarchs who control the state information policy and can influence the quality of the obtained data, while small enterprises do not have a significant impact on indicators or are not taken into account in the research.

There are many ways to calculate real GDP per capita, taking into account negative externalities. According to the OECD (Figure 5), the size of real GDP depends on the condition of the environment and is closely related to the quality of life of the population, which is also an indicator of the introduction of the "green economy" in the world. When comparing real GDP per capita, which partially takes into account the introduction of green technologies and GDP per capita, according to the IMF (2018), which does not take into account the introduction of green technologies, we see a significant difference (Figure 5). 


\section{GDP PER CAPITA, US DOLLAR, 2018}

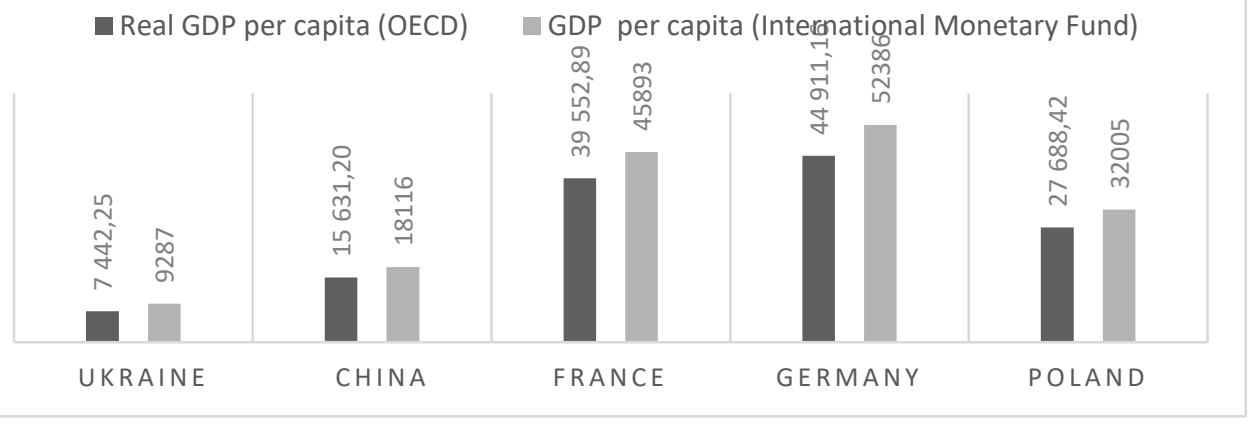

Source: Prepared by the authors based on IMF (2018) and OECD (2019)

From Figure 5 we see that according to the IMF (2018), per capita GDP is on average more than $20 \%$, which indicates a decrease in the economic level by $20 \%$ with the functioning of a market economy without taking into account the deterioration of the environmental component that affects the quality of life of the population, labour potential and other factors, forming the country's GDP.

Based on the obtained data, we can conclude that countries that have taken innovative development as a basis have significantly higher economic indicators and a better state of the ecosystem. Developed innovative countries allocate funds for research and development and encourage entrepreneurs to implement green technologies and develop science. A country like China, which has a high rate of development, but which is due to the deterioration and depletion of natural resources, is not a landmark country. It offers such landmarks for the development of green economies as Germany, Austria, Sweden, France, Canada, some U.S. states that have amended environmental legislation and control over its observance.

In recent years, Israel has joined the developed countries, which in a short period of time and with the introduction of new technologies has become one of the leading countries in the world. Given the corruption component in Ukraine, the slow pace of modernisation, the functioning of heavy industry and already established systems with outdated technologies, changes to the introduction of a green economy will be slower and the path taken by countries with similar stages of development (France, Germany). An effective fight against corruption and the creation of economic and social conditions, these transformations can be carried out faster, based on the experience of Israel in creating new social institutions.

Consider the methodology for calculating the level of implementation of the "green economy" in a country or region under research, which was developed by the authors.

The technological "green economy" implementation coefficient $\left(Z_{T}\right)$ is equal to the sum of the ratio of the number of funds spent on the introduction of clean technologies $\left(T_{e}\right)$ to the total costs of modernising enterprises or their creation and the coefficient of scientific contribution (the ratio of the number of expenditures on the scientific development of clean technologies $\left(\mathrm{N}_{\mathrm{e}}\right)$ to the total amount of expenditure on research $\left.(\mathrm{N})\right)$. 


$$
\mathrm{Z}_{\mathrm{T}}=\frac{\sum_{\mathrm{i}=1}^{\mathrm{n}} \mathrm{T}_{\mathrm{e}}}{\sum_{\mathrm{i}=1}^{\mathrm{n}} \mathrm{T}}+\frac{\sum_{\mathrm{i}=1}^{\mathrm{m}} \mathrm{N}_{\mathrm{e}}}{\sum_{\mathrm{i}=1}^{\mathrm{m}} \mathrm{N}}
$$

where $\mathrm{n}=$ the number of institutions or enterprises introducing new "green" technologies, and $\mathrm{m}$ - is the number of scientific institutions involved in their development.

The human resource coefficient $\left(Z_{\mathrm{I}}\right)$ is equal to the ratio of the difference in the amount of taxes from individuals and legal entities $(P)$ and social expenses for incapacity for work due to morbidity (33) or premature mortality (3c) (three wages per person are taken into account) to the amount of taxes from individuals and legal entities $(P)$ entering the state or local budgets for the studied period of time (for example, by months).

$$
\mathrm{Z}_{\mathrm{l}}=\sum_{\mathrm{i}=1}^{\mathrm{K}} \frac{\mathrm{P}-\left(3_{3}+3_{\mathrm{c}}\right)}{\mathrm{P}} \text {. }
$$

The coefficient of influence on natural resources $\left(Z_{n a t}\right)$ is equal to the ratio of the difference between the profit of the nth number of enterprises (or objects of influence) and the number of funds necessary to spend on returning this resource to a zero state (according to indications of air pollution, condition of water resources, land fund, etc. negative externalities) to the profit of the enterprise.

$$
Z_{\text {nat }}=\sum_{\mathrm{i}=1}^{\mathrm{n}} \frac{\Pi-(\mathrm{A}+\mathrm{B}+\mathrm{C}+\cdots+\mathrm{K})}{\Pi},
$$

where $A$ is the funds needed to recover from air pollution (an example is the installation of modern sewerage systems that do not have a significant impact on the ecosystem), $B$ is the funds needed for recovery from water pollution, $C$ is the funds needed to recover from land pollution (example - the monetary expenditures necessary to recover from the irrational use of fertilisers, debris or depletion of the land fund), D - the funds needed to recover from populations as a result of anthropogenic impact, etc.

The coefficient of the introduction of environmentally friendly transport $\left(Z_{i}\right)$ is equal to the ratio of the number of vehicles that do not adversely affect the ecosystem (electric cars, trolleybuses, etc.) in the researched region to the total number of vehicles (by mode of transport (cars, trucks (depending on tonnage), trains, etc.). In Ukraine, at the moment, it is about 0.002 .

It should also be taken into account the degree of corruption of the country $\left(Z_{k}=C P I / 100\right.$; (0.3 - for Ukraine in 2019)) and the economic development coefficient (for Ukraine in 2018 $0.07): Z_{e}=\frac{\text { GDP per capita of a given country }}{\text { GDP per capita of the country with the highest rate }}$

( 1 in the ranking)

Therefore, the level of implementation of the "green economy" can be calculated as the sum of the coefficients that determine the degree of environmental friendliness in the areas under research:

$$
Z=Z_{T+} Z_{1}+Z_{n a t}+Z_{i}+Z_{k}+Z_{e}
$$

This indicator illustrates the situation in the long-term period, because the higher its value, the higher the level of implementation of the "green economy", which in the long-term period leads to an improvement in the quality of life of the population in all areas and the establishment of a sustainable society, while a decrease in this indicator leads to the 
accumulation of negative impact on the environment and the deterioration of all macroeconomic indicators. According to our estimates, this indicator in Ukraine in 2017 was 0.7 , while in Germany, it was 1.3.

Taking into account the above method of calculating the implementation of the green economy and the situation in Ukraine, we have formed the following recommendations for improving the environment and minimising anthropogenic impact:

A. Continuous study of the state of the environment and the state of implementation of "green technologies" in production, monitoring over time and comparison on five indicators: 1. indicators that characterise the existing natural state of the ecosystem: air pollution, water resources, soils, biodiversity, changes in the quality of human potential, effective capital management and reduction of environmental consequences from anthropogenic impact. 2. Energy efficiency indicators, including energy, construction, housing and communal services, reduction of greenhouse gas emissions; introduction of alternative energy sources. 3. Investment climate and investments in the development of the green economy, including the water supply and sewerage system, public transport focused on alternative fuel sources. 4. Indicators stimulating innovation, including scientific achievements and implementation. 5. Indicators of social responsibility and attitude of the population to innovations.

B. Reforming the system of taxes and fines in order to comply with environmental regulations and legislation, punishing violators by increasing fines for non-compliance with established rules, reducing the tax for innovative "environmentally friendly" enterprises.

C. Adjustment of enterprise performance indicators and macroeconomic indicators in order to assess negative environmental externalities and track general trends and opportunities to increase the speed of implementation of "green technologies".

D. Regulation of tools and standards by their modernisation and adaptation to modern trends.

E. An innovative policy of the state, and change of guidelines, assistance in the adaptation of new ecologically safe enterprises in the conditions of competitiveness and advertising of ecologically safe goods.

F. Social policy taking into account synergetic effects and minimising possible contradictions and contradictions between social, economic and environmental goals, information policy on the implementation of the green economy.

G. Regulation of land use in order to rationally use it and improve quality and productivity, control of landfills and planning of traffic flows and urban areas.

$\mathrm{H}$. Promotion of green tourism and ecological tourism, stimulation of voluntary social actions and ecological protection groups aimed at the development of the green economy and preservation of the ecosystem.

I. Providing compensatory measures for the poor by creating jobs related to the formation of a green economy and encouraging the creation of small businesses, whose activities are aimed at preserving the ecosystem and promoting green technologies, minimisation. Negative externalities. 


\section{DISCUSSION}

Both economic and ecological systems are dynamic, interconnected and transparent, therefore, a change in the indicators of one leads to a change in the other, but at this stage of development, mankind has the means to adjust them, where the target function is to create a system of Green Economy.

The transition to the "green economy" is impossible without sufficient funding, the interest of all business entities, market transparency and technology development, which determine the rate of development, therefore a systematic approach at all levels, starting with every citizen, is extremely important. The usage of grant programs has revealed minor effectiveness in developing countries compared with developed countries, where the government strictly controls environmental standards and affects the development of green technologies, and not only accumulates financial resources.

\section{Conclusions}

Nowadays, technology with minimising negative impact in the ecosystem is developing in the world. Since the natural environment is closely connected with the economic system, influence factors arise that change and result in macroeconomic indicators of countries, forming a new system called the "green economy".

Besides the key instruments of economic policy for the implementation of the "green economy", it is necessary to take into account the existing political situation in the country, the degree of reliability of the information received, and compliance with applicable laws and regulations that must be in place to minimise negative externalities, and not just to maximise profits. Only tough measures of restraint are the best solution to solve the problems when market instruments are unable to achieve goals.

There are many methods for calculating the negative impact on the environment from human activities. However, in our opinion, the best is to use the Pigouvian tax, which is calculated by the cost of bringing the ecosystem to a zero point. With this calculation, a large number of enterprises have effective negative indicators for the negative impact on the environment.

The deterioration of the ecosystem, which is observed mostly in developing countries, can affect the quality of life of the population. It has been determined that in countries where the introduction of the "green economy" is proceeding at a slower pace, the incidence rate, disability and premature mortality rate are higher than in developed countries where the ecological state is the best. All this reduces the country's labour potential, influencing other macroeconomic indicators.

Investing in the development of "green technologies" and the development of resourcesaving systems in developing countries does not guarantee a positive result thanks, firstly, because of the point effect and the lack of long-term financing and interest of all parts of society, and secondly, because of the biased results and non-transparent use of funds with imperfect legislation and its non-compliance, and also because of the existence of corruption schemes. 
The level of implementation of the "green economy" can be calculated as the sum of the coefficients that determine the degree of environmental friendliness in the directions of development of the "green economy". The higher the value of this indicator, the higher the level of introduction of environmentally friendly technologies, high the indicators of the quality of life of the population and the lower incidence thanks to deterioration of the ecosystem, that is, less negative externalities caused by anthropogenic impact on the environment.

\section{References}

Dabyltayeva, N., \& Rakhymzhan, G. (2019). The green economy development path: Overview of economic policy priorities. Journal of Security \& Sustainability Issues, 8(4), 643-651. https://doi.org/10.9770/jssi.2019.8.4(8)

D'Amato, D., Korhonen, J., \& Toppinen, A. (2019). Circular, green, and bio economy: How do companies in land-use intensive sectors align with sustainability concepts? Ecological Economics, 158(April), 116-133. https://doi.org/10.1016/j.ecolecon.2018.12.026

Frone, D.-F., \& Frone, S. (2015). Resource efficiency objectives and issues for a green economy. Scientific Papers Series Management, Economic Engineering in Agriculture and Rural Development, 15, 133.

Grinevich, V., Huber, F., Karatash-Ozkan, M., \& Yavuz, C. (2019). Green entrepreneurship in the sharing economy: Utilising multiplicity of institutional logics. Small Business Economics, 52(4), 859-876. https://doi.org/10.1007/s11187-017-9935-x

$\mathrm{He}, \mathrm{H}$. (2018). Construction and application of mathematical model of energy economy. Chemical Engineering Transactions, 67, 847-85. https://doi.org/10.3303/CET1867142

Kostetska, K., Khumarova, N., Umanska, Y., Shmygol, N., \& Koval, V. (2020). Institutional qualities of inclusive environmental management in sustainable economic development. Management Systems in Production Engineering, 28(1), 15-22. https://doi.org/10.2478/mspe-2020-0003

Koval, V., Mikhno, I., Hajduga, G., \& Gaska, K. (2019). Economic efficiency of biogas generation from food product waste. E3S Web of Conferences, 100(2). https://doi.org/10.1051/e3sconf/201910000039

Mancusi, M. L., Conti, C., Sanna-Randaccio, F., \& Sestini, R. (2018). Transition towards a green economy in Europe: Innovation and knowledge integration in the renewable energy sector. Research Policy, 47(10), 1996-2009. https://doi.org/10.1016/j.respol.2018.07.007

OECD (2019). Mortality, morbidity and welfare cost from exposure to environment-related risks [online]. Retrieved from https://stats.oecd.org/Index.aspx?DataSetCode=EXP_MORSC

Owen, R., Brennan, G., \& Lyon, F. (2018). Enabling investment for the transition to a low carbon economy: Government policy to finance early stage green innovation. Current Opinion in Environmental Sustainability, 31(April), 137-145. https://doi.org/10.1016/j.cosust.2018.03.004

Potravny, I. M., Novoselov, A. L., \& Gengut, I. B. (2016). Formalisation of the general model of green economy at the regional level. R-Economy, 2(2), 225-235. https://doi.org/10.15826/recon.2016.2.2.020

Rodriguez-Anton, J. M., Rubio-Andrada, L., Celemín-Pedroche, M. S., \& Alonso-Almeida, M. D. M. (2019). Analysis of the relations between circular economy and sustainable development goals. International Journal of Sustainable Development \& World Ecology, 26(8), 708-720. https://doi.org/10.1080/13504509.2019.1666754 


\section{DISCUSSION}

Saeed, K. (2018). Towards sustainable development: Essays on system analysis of national policy (2nd ed.). New York, NY: Routledge.

Sandmo, A. (2008). Pigouvian Taxes. In S. Durlauf \& L. Blume (Eds.). The New Palgrave Dictionary of Economics (2nd ed.). New York, NY: W.W. Norton.

Schroeder, P., Anggraeni, K., \& Weber, U. (2019). The relevance of circular economy practices to the sustainable development goals. Journal of Industrial Ecology, 23(1), 77-95. https://doi.org/10.1111/jiec.12732

Sikdar, S. K. (2003). Sustainable development and sustainability metrics. AlChE Journal, 49(8), 19281932. https://doi.org/10.1002/aic.690490802

IMF. (2018). Annual Report. Washington, D.C: International Monetary Fund.

World Bank (2019). GDP per capita (current US\$). Retrieved from https://data.worldbank.org/indicator

Yankovyi, O., Goncharov, Y., Koval, V., \& Lositska, T. (2019). Optimisation of the capital-labor ratio on the basis of production functions in the economic model of production. Naukovyi Visnyk Natsionalnoho Hirnychoho Universytetu, 4, 134-140. https://doi.org/10.29202/nvngu/2019-4/18

Yeshchenko, M., Koval, V., \& Tsvirko, O. (2019). Economic policy priorities of the income regulation. Espacios, $40(38), \quad 11 . \quad$ Retrieved from https://www.revistaespacios.com/a19v40n38/a19v40n38p11.pdf

Newton, A. C., \& Cantarello, E. (2014). An introduction to the green economy: Science, systems and sustainability. Routledge.

The discussion paper passed the review process. | Received: April 11, 2020; Revised: May 21, 2020; Accepted: July 16, 2020; Pre-published online: December 22, 2020; Published: March 19, 2021. 